\title{
EFFECT OF PELVICALICEAL ANATOMY ON "POST ESWL STONE CLEARANCE OF LOWER CALICEAL STONE"
}

\author{
MD. MUZHARUL HOQ ${ }^{1}$, S.M. MAHBUB ALAM ${ }^{2}$, MAAWAL ${ }^{2}$, MD. AMANUR RASUL ${ }^{2}$, PRANASHIS SAHA ${ }^{3}$, \\ FAISAL ISLAM ${ }^{3}$, SHARIF SHAHJAMAL ${ }^{3}$, ABID HOSSAIN ${ }^{3}$
}

${ }^{1}$ Junior consultant of Surgery, Upazila Health complex, Patiya, Chittagong, ${ }^{2}$ Professor \& Head, Department of Urology, Dhaka Medical College Hospital, Dhaka, Bangladesh, ${ }^{3}$ Department of Urology, NIKDU, Dhaka

\begin{abstract}
Objective: To find out stone clearance rate of lower calyx and to determine important anatomic predictive factors responsible for the stone clearance of lower calyx following ESWL.

Methods: This prospective quasi experimental study was conducted in the Department of Urology, Dhaka Medical College Hospital, Dhaka, from January 2006 to July 2007. Patients with single lower calyceal stone (Stone size d" 20mm), age between 12 to 75 years and were agreed to participate in the study were selected. Different lower calyceal predictive factors were measured from IVU with the help of radiologist before ESWL. Selected patients were treated with ESWL by siemens lithostar machine in the department of Urology, Dhaka Medical College Hospital. Patients were discharged on the same day with advice to follow up after 1 month. All patients were followed up with plain X-ray KUB region to see stone clearance. Purposive sampling methods were followed. Data were processed and analyzed using software SPSS (Statistical Package for Social Sciences).

Results: Lower caliceal stones with favorable anatomy (infundibulo-pelvic angle e" $70^{\circ}$, infundibular length d" $30 \mathrm{~mm}$, infundibular diameter $>4 \mathrm{~mm}$, and infundibular length to diameter ratio < 7) were stone free in cases and was statistically significant in stone clearance. But number of minor calices, caliceal pelvic height and stone morphology have shown no impact on stone clearance in this study.
\end{abstract}

Conclusion: ESWL for lower caliceal stone should be recommended only those patients those have favorable anatomy for discharge of fragments.

Key words: Lower caliceal stone; ESWL; stone morphology.

Bangladesh J. Urol. 2012; 15(1): 6-10

\section{Introduction}

Urinary stones have plagued human being since the beginning of recorded history. Archaeologists have uncovered urinary stones from Egyptian mummies, estimated to be more than 7000 years old. Since then, humans have sought improved methods for dealing with stones ${ }^{1,2}$. Currently urinary stone formation affects 10 to $12 \%$ of the population, the peak incidence seems to be at ages 20 to 40 years, ratio among male and female is $3: 1$, geographically more common in northern part of our country and ranked third of all urological diseases ${ }^{2,3,4}$. Initially open surgery was the main stay

Correspondences: Dr. Md. Muzharul Hoq, Junior consultant of Surgery, Upazila Health Complex, Patiya of management of urinary stone disease. Now extracorporeal shock wave lithotripsy (ESWL) and endourological procedures virtually eliminates open surgical procedures ${ }^{5}$. Extracorporeal shock wave lithotripsy was first introduced for the treatment of stone disease in February 1980 in Germany by Dornier Company ${ }^{6}$. The goal of ESWL is the creation of stone fragments that are smaller than one $\mathrm{mm}$, which can pass spontaneously and painlessly from the urinary tract ${ }^{7,8}$. The majority of (about 80 to $85 \%$ ) of simple renal calculi (d"2cm) can be treated satisfactorily with ESWL. There is a general consensus that the treatment of lower caliceal stones by ESWL has a poor success rate ${ }^{9}$. Sampaio \& Aragao $(1992)^{10}$, Elbahansy et al. (2002) ${ }^{11}$ and Sumino et al $(2002)^{12}$ all had shown that the lower pole anatomy might be responsible for retention of stone fragments. 


\section{Methods}

This prospective quasi experimental study was conducted in the Department of Urology, Dhaka Medical College Hospital, Dhaka, from January 2006 to July 2007. Patients with single lower caliceal stone (Stone size d" $20 \mathrm{~mm}$ ), age between 12 to 75 years and were agreed to participate in the study were selected. Patients having with stones in other sites of urinary tract i.e. renal pelvis, other calyces, caliceal diverticulum, ureter, urinary bladder, extreme age ( $<12$ years and $>75$ years), Stone size $>20 \mathrm{~mm}$, multiple lower caliceal stones, any anatomical abnormality of urinary tract, congenital anomalies of the skeleton, obstructed kidney leading to any degree of hydronephrosis, morbid obesity of the patient, history of previous surgery on affected kidney, patient refuse to give consent were excluded from the study. Different lower caliceal predictive factors were measured from IVU with the help of radiologist before
ESWL and they were recorded in a prescribed proforma. Selected patients were treated with ESWL by siemens lithostar machine in the department of Urology, Dhaka Medical College Hospital. Patients were discharged on the same day with advice to follow up after 1 month. All patients were followed up with plain X- ray KUB region to see stone clearance. Purposive sampling methods were followed. Data were processed and analyzed using software SPSS (Statistical Package for Social Sciences).

\section{Results}

A total of 67 patients of lower caliceal stone who underwent ESWL were included in the study. Of them 7 patients did not attend at follow up session after 1 month leaving 60 for final analysis. The patients who exhibited complete clearance of stone at 1 month follow up were termed as stone-free group, while patients who had fragments of stones after same period of time were assigned to residual stone group.

\section{Demographic variables}

Table-I

Shows different demographic variables.

\begin{tabular}{lcc}
\hline Age & Range 17- 80 years & Mean 42.6 \pm 13.1 years \\
\hline Sex & Male $-40(67 \%)$ & Female $-20(33 \%)$ \\
Social status & Upper and middle class 39(65\%) & Lower class 21(35\%) \\
Kidney involved & Right 27 $(45 \%)$ & Left 33 $(55 \%)$ \\
Stone clearance & Residual stone 25 $(42 \%)$ & Stone free 35 $(58 \%)$ \\
\hline
\end{tabular}

About $65 \%$ patients belong to $3^{\text {rd }}$ and $6^{\text {th }}$ decade of life. Two third of the subjects were male and one third were female and male and female ratio was 2:1.

\section{Lower pole renal collecting system anatomy:}

Table II compares the lower pole collecting system anatomical parameters between patients of stone-free and patients having residual stone.

Table-II

Comparison of lower pole anatomy between groups

\begin{tabular}{lccc}
\hline Lower pole collecting system anatomy & \multicolumn{2}{c}{ Outcome } & $p$-value \\
& Stone-free $(\mathrm{n}=35)$ & Residual stone $(\mathrm{n}=25)$ & \\
\hline Infundibular length $(\mathrm{mm})$ & $27.60 \pm 3.13$ & $30.16 \pm 2.70$ & 0.002 \\
Infundibular diameter $(\mathrm{mm})$ & $4.61 \pm 0.43$ & $3.98 \pm 0.45$ & $<0.001$ \\
Infundibulo-pelvic angle (degree) & $82.26 \pm 7.93$ & $69.52 \pm 8.95$ & $<0.001$ \\
Caliceal-pelvic height $(\mathrm{mm})$ & $24.00 \pm 4.39$ & $25.76 \pm 1.76$ & 0.063 \\
No. of minor calices & $2.74 \pm 0.82$ & $2.88 \pm 0.88$ & 0.537 \\
Infundibular length to diameter ratio & $6.02 \pm 0.78$ & $7.67 \pm 1.01$ & $<0.001$ \\
\hline
\end{tabular}

Figures in the parentheses denote corresponding \%. \#Data were analyzed using Student's t-Test and level of significance was 0.05 . 
Effect of Pelvicaliceal Anatomy on "Post Eswl Stone Clearance of Lower Caliceal Stone"

Table-III

Comparison of stone morphology between groups

\begin{tabular}{lccc}
\hline Stone morphology & \multicolumn{2}{c}{ Outcome } & p-value ${ }^{\#}$ \\
\cline { 2 - 3 } & Stone-free $(\mathrm{n}=35)$ & Residual stone $(\mathrm{n}=25)$ & \\
\hline Length of stone & $14.59 \pm 2.16$ & $12.76 \pm 2.35$ & 0.398 \\
Width of stone & $11.26 \pm 2.11$ & $10.00 \pm 2.38$ & 0.940 \\
Stone surface area & $143.03 \pm 46.38$ & $132.40 \pm 53.55$ & 0.868 \\
\hline
\end{tabular}

\#Data were analyzed using Student's t-Test and level of significance was 0.05 .

\section{Stone morphology:}

None of parameters of stone morphology like length of stone, width of stone and stone surface area tend to be associated with clearance of stone following ESWL $(p=$ $0.398, p=0.940$ and $p=0.868$ respectively) (Table III).

\section{Favorable and unfavorable lower pole collecting system anatomy:}

Combined evaluation of lower pole anatomical features shows that $80 \%$ of the stone-free group had favorable anatomy (infindibular length $30 \mathrm{~mm}$ or less, infundibular diameter $>4 \mathrm{~mm}$, infundibular length to diameter ratio < 7 , infundibulo-pelvic angle 70 degrees or greater and $<$ 3 minor calyces) compared to only $12 \%$ of those who had residual stone $(p<0.001)$ (Table V).

\section{Table-V}

Comparison of favorable and unfavorable lower pole anatomy between groups $(n=60)$

\begin{tabular}{lccl}
\hline $\begin{array}{l}\text { Lower pole } \\
\text { anatomy }\end{array}$ & $\begin{array}{c}\text { Outcome } \\
\text { Stone-free } \\
(\mathrm{n}=35)\end{array}$ & $\begin{array}{c}\text { Residual stone } \\
(\mathrm{n}=25)\end{array}$ & -value $^{\#}$ \\
\hline Unfavorable & $7(20.0)$ & $22(88.0)$ & \\
Favorable & $28(80.0)$ & $3(12.0)$ & $<0.001$ \\
\hline
\end{tabular}

Figures in the parentheses denote corresponding \%. \# Data were analyzed using Chi-square $(\chi 2)$ Test and level of significance was 0.05 .

\section{Discussion}

The present study has designed to compare the different anatomical predictors of lower calyx for stone clearance and try to find out most important anatomical factor or factors responsible for stone clearance. Mean age \pm SD of the subjects of present study was $42.2 \pm 13.1$ years and median age was 40.2 years. Age range of this study was 17 to 80 years. Kupeli et al. ${ }^{19}$ \& Ather, Memon \& Sulaiman ${ }^{20}$ studied on 42 and 518 patients respectively and found mean age \pm SD was $40.8 \pm 10.3$ and $38.6 \pm$
12.2 years and age range was 23 to 73 years. Present study shows that the stone clearance rate after one month of ESWL was about $58 \%$ (35 patients) and $42 \%$ (25 patients) had residual stone. In a meta analysis Lingeman et al. ${ }^{14}$ noted that overall stone free rate of lower pole stones treated with shock wave lithotripsy were $59 \%$. Srivastava et al. ${ }^{21}$ had shown that the stone clearance of lower pole calculi was $25-85 \%$. They argued that, that variability of the stone retention was due to fragment retention rather than stone disintegration 21.22.

Mean infundibular length $\pm S D(\mathrm{~mm})$ in stone free group was $27.60 \pm 3.13$. On the other hand in residual stone group it was $30.16 \pm 2.70$ and $p$-value among the two groups $p$-value was .002 . Sumino et al. ${ }^{12}$ and Srivastava et al. ${ }^{21}$ showed in their study that mean infundibular length $\pm S D(\mathrm{~mm})$ in stone free group was $25.3 \pm 0.7$ and $24.56 \pm 5.65$. and residual stone group was $29 . \pm 1.1$ and $28 \pm 1.34$ respectively and their $p$-value were .005 . This result correlates with the present study. Present study shows that the mean infundibular diameter \pm SD $(\mathrm{mm})$ was $4.61 \pm 0.43$ in stone free group and $3.98 \pm 0.45$ in residual stone group and $p$-value was $<.001$. Sumino et al. ${ }^{12}$ had shown that mean lower infundibular diameter was $4.9 \pm 0.3$ in stone free group and $3.9 \pm 0.4$ in residual stone group and their $p$-value was 0.01 . Present study shows that the mean infundibulo-pelvic angle $\pm S D$ (degrees) in stone free group was $82.26 \pm 7.93$ but in residual stone group was $65.52 \pm 8.95$ and the $p$-value was $<0.001$. Elbahnasy et al. ${ }^{11}$ showed that the infundibulo-pelvic angle $\pm S D$ (degrees) in stone free group was $85.2 \pm 8.16$. This'result correlates 'with present study. In this study the mean caliceal-pelvic height $\pm S D$ $(\mathrm{mm})$ was $24.00 \pm 4.39$ in stone free group and $25.76 \pm 1.76$ in residual stone group. Their $p$-value was 0.063 . Sumino et al. ${ }^{12}$ showed that, in stone free group mean calicealpelvic height $\pm S D(\mathrm{~mm})$ was $23.8 \pm 1.0$ and stone free group it was $26.4 \pm 1$. Mean number of minor calices $\pm S D$ in this study was $2.74 \pm 0.82$ in stone free group and $2.88 \pm 0.88$ in residual stone group. Their $p$-value was 
0.537. Srivastava et al. ${ }^{21}$ showed that the mean number of minor calices were $2.74 \pm 0.54$ in stone free group and $3.04 \pm 0.47$ in residual stone group. P-value of that study was 0.56 . Both the studies had shown that the minor calices had no impact on stone clearance. This study has shown that the mean infundibular length to diameter ratio $\pm S D$ was $6.02 \pm 0.78$ in stone free group and $7.67 \pm 1.01$ in residual stone group. Their $p$-value was $<0.001$. Sumino et al. ${ }^{12}$ showed that mean lower infundibular length to diameter ratio $\pm S D$ was $5.8 \pm 0.04$ in stone free group and $9.8 \pm 1.1$ in residual stone group and $p$-value was $<0.001$. Present study shows that 45 $(75 \%)$ patients had wide infundibulo-pelvic angle $\left(e^{\prime \prime} 70^{\circ}\right)$ and their stone clearance was $69 \%$.On the other hand $15(25 \%)$ patients had narrow angle $\left(<70^{\circ}\right)$ and their stone clearance rate was only $27 \%$. Sampaio \& Aragao 10 and Sabnis et al. ${ }^{23}$ reported in their series that $74.0 \%$ and $75.61 \%$ respectively patients had wide infundibulopelvic angle and remaining $26 \%$ had narrow infundibulopelvic angle. This result correlates with the present study. Sabnis et al. ${ }^{23}$ found $75.61 \%$ patients had wide infundibulo-pelvic angle $\left(\mathrm{e}^{\prime \prime} 70^{\circ}\right)$ and their stone clearance rate was $88.75 \%$. On the other hand, $24.39 \%$ had narrow infundibulo-pelvic angle $\left(<70^{\circ}\right)$ and their stone clearance rate was $12.38 \%$. In this study the number of minor calices and stone morphology had no impact on stone clearance. Sampaio \& Aragao ${ }^{10}$, Srivastava et al. ${ }^{21}$ and Sabnis et al. ${ }^{23}$ also confirmed this argument. In this study it has shown that $31(51.66 \%)$ patients had favorable anatomy and 29 (49.34\%) patients had unfavorable anatomy. Those who had favorable anatomy $80 \%$ became stone free and those with unfavorable anatomy $20 \%$ were stone free. Sorensen \& Chandhoke 24. showed that the patients with favorable anatomy (lower pole infundibulo-pelvic angle e" $70^{\circ}$, lower pole infundibular length d" $30 \mathrm{~mm}$ or lower infundibular width $>5 \mathrm{~mm}$ ) had an $94 \%$ chance of being stone free versus a $39 \%$ chance with unfavorable anatomy (lower pole infundibulo-pelvic angle, lower pole infundibular length or lower infundibular width $<70^{\circ},>30 \mathrm{~mm}$ or d" $5 \mathrm{~mm}$ respectively).

\section{Conclusion}

From the present study it is concluded that the patient with infundibulo-pelvic angle e" $70^{\circ}$, infundibular length d" $30 \mathrm{~mm}$, infundibular diameter $>4 \mathrm{~mm}$, and infundibular length to diameter ratio $<7$ is recommended for ESWL for lower calyceal stone.

\section{Conflict of Interest : None Declared}

\section{References}

1. Anglade, RE, Wang, DS \& Babyan, RK. Urinary calculi and Endo-urology. Hand book of UrologyDiagnosis and therapy. $3^{\text {rd }}$ edition. Lippincott Williams and Wilkins, Philadelphia, 2005; P 232248.

2. Gurocak, S\& Kupeli, B., Consumption of historical and current phytotherapeutic agents for urolithiasisCritical review. J Urol. 2006; 176:2, 450-455 .

3. Salam, MA. Urinary stone disease, Principles and Practice of urology-A comprehensive text book. $1^{\text {st }}$ edition. MAS publication, Dhaka, 2002; P 721-740.

4. Stroller, ML. Urinary stone disease. Smith's General Urology, $16^{\text {th }}$ edition. Lange Medical Books/Mc Grawhill; New York, 2004; P 256-290.

5. Pearle, MS \& Lotan, Y. Urinary Lihiasis, Etiology, Epidemiology and Pathogenesis. Campbell-Walsh Urology, $9^{\text {th }}$ edition, Saunders Elsevier, 2007; Vol 2, P 1363-1392.

6. Russel, RCG, Williams, NS \& Bulstrode, CJK. The kidneys and ureters, Bailey and Love's Short practice of surgery. $24^{\text {th }}$ edition, Arnold publisher, London, 2004; P1315-1321.

7. Wilbert, DM. A comparative review of extracorporeal shock wave generator. BJU International. 2002; 90, 507-511.

8. Grassow, M \& Sapliviero, M. Extracorporeal shock wave lithotripsy, e-medicine (on line), [30 July2006], Available from: http://www. E medicine .com.

9. Kanao, K, Nakashima, J, Nakagawa, K, Asakura, $\mathrm{H}$, Miyajima, A, Oya, M, Ohigashi, T \& Murai, M. Preoperative normograms for predicting stone free rate after extracorporeal shock wave lithotripsy. J Urol. 2006; 176: 1453-1457.

10. Sampaio, FJB \& Aragao, AHM. Inferior pole collecting system anatomy: Its probable role in extracorporeal shock wave lithotripsy. J Urol. 1992; 147: 322-324.

11. Elbahnasy, AM, Shalhab, AL, Hoenig, DM, Elashry, OM, Smith, DS, Mcdougall, EM \& Clayman, RV. Lower caliceal stone clearance after shock wave lithotripsy or ureteroscopy: The impact of lower pole radiographic anatomy. J Urol. 1998; 159: 676-682.

12. Sumino, $\mathrm{Y}$, Mimata, $\mathrm{H}$, Tasaki $\mathrm{Y}$, Ohno, $\mathrm{H}$, Hoshino, T, Nomura, T \& Nomura, Y. Predictors of lower pole renal stone clearance after extra 
corporeal shock wave lithotripsy. J Urol. 2002; 168: 1344-1347.

13. Tolly, DA \& Downey, P. Current advances in shock wave lithotripsy, Current Opin Urol. 1999; 9, 319323.

14. Lingeman, JE, Siegel, YI \& Steele, B. Management of lower pole nephrolithiasis: A critical analysis . J Urol. 1994; 151: 663-667.

15. Renner, $\mathrm{CH} \&$ Rassweiler, J. Treatment of renal stones by Extracorporeal Shockwave Lithotripsy. Nephron. 1999; 81: 71-81

16. Cass, AS, Grine, WB, Jenkins, JM, Jordan, WR, Mobley, TB \& Nyers, DA. The incidence of lower pole nephrolithiasis increasing or not. British Journal of Urology. 1998; 82, 12-15.

17. Carr, LK, Honey, J \& Jewett, MA. New stone formation, A comparison of Extracorporeal shockwave lithotripsy and percutaneous nephrolithotomy. J Urol. 1996; 155: 1565-1567.

18. Tuckey, J, Devasia, A, Murthy, L, Ramsden, P \& Thomas, D. Is there a simpler method for predicting lower pole stone clearance after shockwave lithotripsy than measuring infudibulopelvic angle? J Endourol. 2000; 14: 475.

19. Kupeli, B, Tunc, L, Alkibay, T, Karaoglan, U \& Bozkirli, I. Pelvicalyceal stone load: a factor affecting the outcome of extracorporeal shock wave lithotripsy for renal pelvic calculi. BJU International. 2001; 88, 854-857.

20. Ather, MH, Memon, JP \& Sulaiman, MN. A 10year experience of managing ureteric calculi: changing trends towards endourological intervention - is there a role for open surgery. BJU International. 2001; 88, 173-177.

21. Srivastava, A, Zaman, W, Singh, V, Kumar, A \& Singh, A. Efficacy of extracorporeal shock wave lithotripsy for solitary lower calyceal stone: a statitstical model. BJU International. 2004; 93: 364-368.

22. Lingeman, JE, Matlaga, BR \& Evan, AP. Surgical Management of upper urinary tract calculi. Campbell-Walsh Urology, $9^{\text {th }}$ edition, Saunders Elsevier. 2007; Vol 2: P 1431-1507.

23. Sabnis, B, Naik, K, Patel, SH, Desai, MR \& Bapat, SD. Extracorporeal shock wave lithotripsy for lower calyceal stones: can clearance be predicted? BJU. 1997; 80: 853-857.

24. Sorensen, CM \& Chandhoke, PS. Is lower pole caliceal anatomy predictive of extracorporeal shock wave lithotripsy success for primary lower pole kidney stones? The Journal of Urology.2002; 168: 2377-2382.

\section{Abbreviations}

$\mathrm{ESWL}=$ Extracorporeal shock wave lithotripsy 